\title{
Proton-assisted dissociation of a triple-stranded dinuclear europium helicate $\dagger$
}

\author{
Mourad Elhabiri, ${ }^{a}$ Josef Hamacek, ${ }^{a}$ Nicolas Humbert, ${ }^{a}$ Jean-Claude G. Bünzli ${ }^{b}$ and \\ Anne-Marie Albrecht-Gary*a
}

${ }^{a}$ Laboratoire de Physico-Chimie Bioinorganique, UMR 7509 du CNRS, ECPM, Université

Louis Pasteur, 25 rue Becquerel 67200 Strasbourg, France.

E-mail: amalbre@chimie.u-strasbg.fr; Fax: 33 (0) 3902426 39; Tel: 33 (0) 390242638

${ }^{b}$ Swiss Federal Institute of Technology Lausanne, Laboratory of Lanthanide Supramolecular

Chemistry, BCH 1402 CH-1015 Lausanne, Switzerland.E-mail: jean-claude.bunzli@epfl.ch; Fax: 4121693 9825; Tel: 41216939821

Received (in Montpellier, France) 20th April 2004, Accepted 8th June 2004

First published as an Advance Article on the web 16th August 2004

\begin{abstract}
A fruitful combination of absorption and gated luminescence spectrophotometry allowed us to gain insight into the proton-assisted dissociation of a triple-stranded dinuclear europium helicate in water. This process involves a key dimetallic double-stranded complex $\mathrm{Eu}_{2} \mathrm{~L}_{2}$ as already observed in the self-assembly process of the triple helicate. The slow unravelling of the first strand, which is triggered by the protonation of its two carboxylate groups, dominates the whole disentangling mechanism of the supramolecular edifice. The solvolytic dissociation in water is rather slow $\left(k_{\mathrm{D}}=4(1) \times 10^{-4} \mathrm{~s}^{-1}\right)$ and is catalysed by $\mathrm{H}^{+}$ions $\left(k=0.12(3) \mathrm{M}^{-1} \mathrm{~s}^{-1}\right)$. These lanthanide helicates, which are characterised by high kinetic inertness over a wide range of $\mathrm{pH}$ and high thermodynamic stability in water, are promising building blocks for the development of novel fluorescent biomarkers.
\end{abstract}

\section{Introduction}

During the last decades, the peculiar magnetic and spectroscopic properties of trivalent lanthanide ions, ${ }^{1} \mathrm{Ln}(\mathrm{III})$, have attracted considerable interest for the design of probes and responsive systems for biomedical analyses, ${ }^{2}$ medical diagnosis and therapy. ${ }^{3}$ For instance, contrast agents based on gadolinium(III) chelates are commonly used for enhancing the quality of MRI medical images. ${ }^{3 b}$ Furthermore, the long excited state lifetimes of several Ln(III) ions are ideally suited for the engineering of immunoassays using time-resolved luminescence for the separation of the probe phosphorescence from the background fluorescence. ${ }^{2 \mathrm{a}, \mathrm{b}}$ Finally, stimulating developments are presently taking place in which lanthanide probes emitting in the visible allow the imaging of cancer cells, ${ }^{4}$ and this methodology is being extended to the near infrared $(\mathrm{Nd}, \mathrm{Er}, \mathrm{Yb})$, a spectral range in which biological tissues have little absorption. ${ }^{5}$

These applications require the design of lanthanide chelates with high thermodynamic stability and kinetic inertness under physiological conditions. In addition, the molecular programming of lanthanide-containing stains should aim at controlling, or possibly enhancing, the physico-chemical properties of the $4 \mathrm{f}$ ions. Therefore, a strict command of the inner co-ordination sphere is needed, which represents a real challenge in view of the poor stereochemical requirements of the $\operatorname{Ln}(\mathrm{III})$ ions, as well as of their large and variable co-ordination numbers. Several different synthetic strategies have been successfully proposed to achieve this goal. One approach uses multiplestep convergent syntheses to produce adequate receptors and self-assembly processes to lead to triple helical monometallic complexes or to polymetallic helicates. ${ }^{6}$ In this way, interesting

$\dagger$ Electronic supplementary information (ESI) available: experimental data. See http://www.rsc.org/suppdata/nj/b4/b405934d/ homo- $(4 f-4 f)^{7}$ and hetero ( $4 f-4 f^{8}$ or $4 f-3 d^{5 b}$ ) dimetallic functional edifices have been isolated. ${ }^{9}$ We note that the advantage of hetero dimetallic helicates is their potential use as bi-colour luminescent probes or as compounds acting simultaneously as magnetic and spectroscopic stains. The same strategy can be fruitfully extended to trimetallic $4 \mathrm{f}-4 \mathrm{f}-4 \mathrm{f}$ architectures. ${ }^{10}$

Until now, thermodynamic, structural and spectroscopic properties of metal-containing dimetallic helicates have been extensively studied, contrary to their kinetic properties, apart from our on-going work on supramolecular edifices with polytopic ligands. ${ }^{11-14}$ In particular, we have recently fully elucidated the self-assembly mechanism leading to the exclusive formation of a triple-stranded dimetallic helicate $\mathrm{Eu}_{2} \mathrm{~L}_{3}$ in water (Figure S1, ESI), where L is bearing two symmetrical tridentate units (O-carboxylate, N-pyridyl, N-benzimidazolyl, Fig. 1). ${ }^{11}$

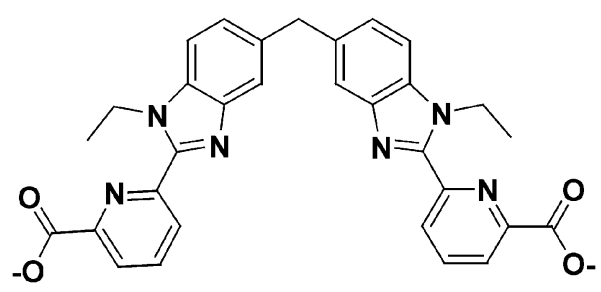

Fig. 1 Chemical formula of the deprotonated transoid ligand L.

The mechanism proceeds through either one of $\mathrm{EuL}_{2}$ or $\mathrm{Eu}_{2} \mathrm{~L}$ intermediates, depending on the experimental conditions, and leads to $\mathrm{Eu}_{2} \mathrm{~L}_{2}$ by a "braiding" or a "keystone" mechanism. Finally, $\mathrm{Eu}_{2} \mathrm{~L}_{2}$, which was found to be very inert towards the release of either a ligand molecule or a cation, reacts very fast with a third ligand strand leading to the targeted $\mathrm{Eu}_{2} \mathrm{~L}_{3}$ helicate (Fig. 2). The overall process is mainly governed by electrostatic interactions. ${ }^{11}$ 

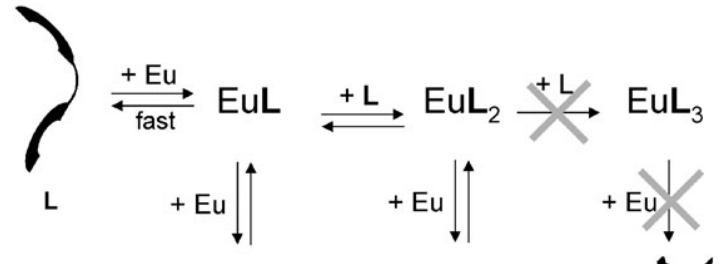

but

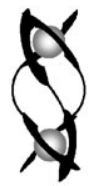

$\mathrm{Eu}_{2} \mathrm{~L}_{3}$

Fig. 2 Schematic representation of the self-assembly mechanism of $\mathrm{Eu}_{2} \mathrm{~L}_{3}$. ${ }^{11}$

The stability of the $4 \mathrm{f}-4 \mathrm{f}$ dimetallic edifices towards acidpromoted hydrolysis is important in the context of their use as analytical probes. Therefore, we present in this paper a detailed study of the $\mathrm{Eu}_{2} \mathrm{~L}_{3}$ dissociation under acidic conditions. We rely on a combination of spectrophotometry and gated luminescence, as well as on stopped-flow techniques, to determine the kinetic parameters related to the proton-assisted dissociation of $\mathrm{Eu}_{2} \mathrm{~L}_{3}$ in water and propose a reaction mechanism.

\section{Results and discussion}

\section{Properties of ligand L and dinuclear europium(III) triple- stranded helicate}

In our previous studies, three protonation constants have been determined for L: $\log K_{\mathrm{LH}}=10.1(1), \log K_{\mathrm{LH}_{2}}=9.5(2)$, and $\log$ $K_{\mathrm{LH}_{3}}=6.0$ (2) and we have assigned them to the two imidazolyl groups and to a pyridyl function, respectively. ${ }^{11}$ The poor solubility below $\mathrm{pH}=6$ and the precipitation of the ligand $\mathrm{L}$ at $\mathrm{pH}=4$ prevent the determination of the other protonation constants which were estimated to be at about 5.4 for $\log K_{\mathrm{LH}_{4}}$ and lower than 2 for $\log K_{\mathrm{LH}_{5}}$ and $\log K_{\mathrm{LH} 6 .}{ }^{15}$ Under very acidic conditions, below $\mathrm{pH}=2$, $\mathrm{L}$ re-dissolves, due to protonation of the carboxylate functions. The formation of the helicate induces a significant red shift to $332 \mathrm{~nm}$ of the ligand $\pi \rightarrow \pi^{*}$ transition centred at $308 \mathrm{~nm}$ (Figure S2, ESI).

The ditopic ligand $\mathrm{L}$ acts also as a fair sensitiser of the $\mathrm{Eu}(\mathrm{III})$ luminescence, the absolute quantum yield of the metalcentred luminescence (Fig. 3) reaching $1.3 \%$ at $\mathrm{pH} \approx 7.0$, with a detection limit of $10^{-9} \mathrm{M}$ in $\mathrm{H}_{2} \mathrm{O}$ and $10^{-11} \mathrm{M}$ in $\mathrm{D}_{2} \mathrm{O} .^{7 \mathrm{~d}}$

\section{Kinetic data}

The global de-complexation reaction, under acidic conditions, can be written as follows (charges are omitted throughout this

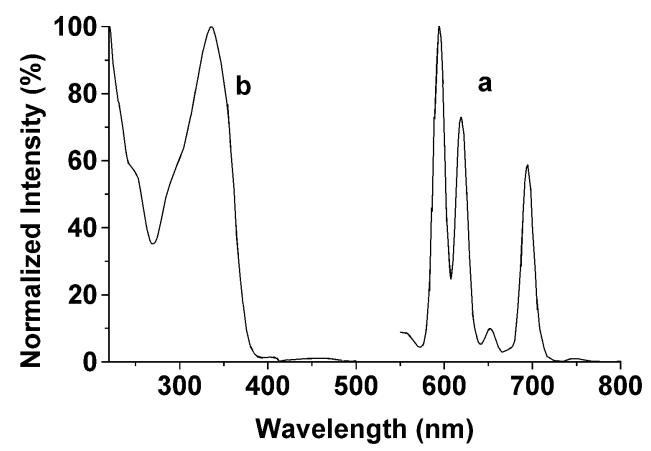

Fig. 3 Gated luminescence spectra of $\mathrm{Eu}_{2} \mathrm{~L}_{3}\left[\mathrm{Eu}_{2} \mathrm{~L}_{3}\right]_{\text {tot }}=1.2 \times 10^{-6}$ $\mathrm{M}$ in water, at $25.0 \pm 0.2^{\circ} \mathrm{C}$ and $\mathrm{pH}=6.0$. (a) Emission spectrum $\lambda_{\mathrm{exc}}=$ $332 \mathrm{~nm}$. (b) Excitation spectrum $\lambda_{\mathrm{an}}=595 \mathrm{~nm}$.
Table 1 Variations of the pseudo-first-order rate constants $k_{\mathrm{obs}}$ for the dissociation of $\mathrm{Eu}_{2} \mathrm{~L}_{3}$ in water at $25.0 \pm 0.2{ }^{\circ} \mathrm{C}$, versus $\left[\mathrm{HClO}_{4}\right]_{\text {tot }}$

\begin{tabular}{lc}
\hline$\left[\mathrm{HClO}_{4}\right]_{\mathrm{tot}} / \mathrm{mM}$ & $k_{\mathrm{obs}} \times 10^{3} / \mathrm{s}^{-1 a}$ \\
\hline 46.5 & $2.2(8)$ \\
93 & $8.8(8)$ \\
111 & $13(2)$ \\
185 & $26(2)$ \\
278 & $39(2)$ \\
371 & $47(2)$ \\
417 & $51(3)$ \\
464 & $54(2)$ \\
540 & $57(2)$ \\
556 & $60(2)$ \\
649 & $65(2)$ \\
742 & $71(2)$ \\
834 & $75(4)$ \\
${ }^{a}$ From absorbance data at 345 nm; $\left[\operatorname{Eu}_{2} \mathrm{~L}_{3}\right]_{\mathrm{tot}}=$ & $7.22 \times 10^{-6} \mathrm{M}$. \\
Uncertainties are given within parentheses $(3 \sigma)$. & \\
\hline
\end{tabular}

paper for the sake of simplicity):

$$
\mathrm{Eu}_{2} \mathrm{~L}_{3}+18 \mathrm{H} \rightarrow 2 \mathrm{Eu}+3 \mathrm{LH}_{6}
$$

In a first series of experiments, the absorbance at $345 \mathrm{~nm}$, which corresponds to the maximum of spectrophotometric amplitude (Figure S2, ESI), was monitored versus time for several concentrations of perchloric acid in the range $0.046 \mathrm{M}$ $<\left[\mathrm{H}^{+}\right]<0.834 \mathrm{M}$. In all the cases, the variation could be fitted with a single exponential function (Figure S3, ESI); the corresponding pseudo-first-order rate constants are reported in Table 1 and in Figure S4 (ESI).

In order to check whether or not other processes take place during the dissociation, we have also recorded the time dependence of the entire absorption spectra (280-400 nm) by stopped-flow techniques. An isosbestic point is clearly observed at $324 \mathrm{~nm}$ (Fig. 4) between the spectra of the protonated helicate and of the free protonated ligand. Furthermore, when the spectra are recorded on a longer time span (up to $1000 \mathrm{~s}$ ) a second, slow process is evidenced, in which the ligand is apparently degraded. A control experiment on the ligand alone confirmed this slow decomposition, in which carbon dioxide is released (Figures S5 and S6, ESI).

We have also taken advantage of the europium-centred luminescence to monitor the dissociation process and to confirm the rate constants extracted from the absorption spectra. The decay of the ${ }^{5} \mathrm{D}_{0} \rightarrow{ }^{7} \mathrm{~F}_{1}$ transition is a single exponential curve (Figure S7, ESI) over the entire concentration range of the acid and the calculated pseudo-first-order constants are reported on Fig. 5 (see also Table S1, ESI). They compare very well with those determined by absorption spectrophotometry.

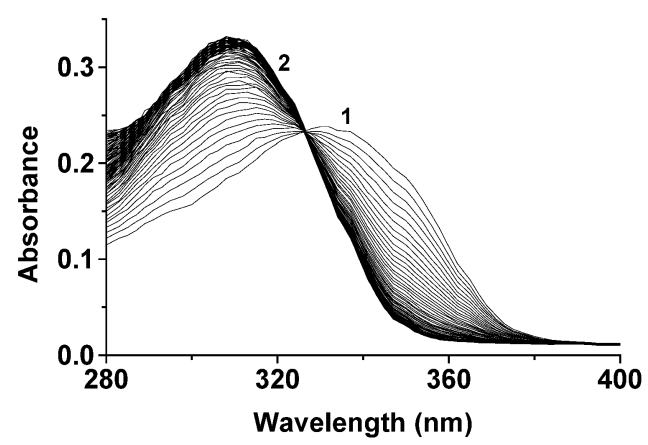

Fig. 4 Absorbance spectra recorded during the acid dissociation of $\mathrm{Eu}_{2} \mathrm{~L}_{3}$ in water at $25.0 \pm 0.2{ }^{\circ} \mathrm{C}$; $\left[\mathrm{Eu}_{2} \mathrm{~L}_{3}\right]_{\text {tot }}=1.51 \times 10^{-5} \mathrm{M}$; $\left[\mathrm{HClO}_{4}\right]_{\mathrm{tot}}=0.2 \mathrm{M}$; (1) $t=0.163 \mathrm{~s}$; (2) $t=250 \mathrm{~s}$. 


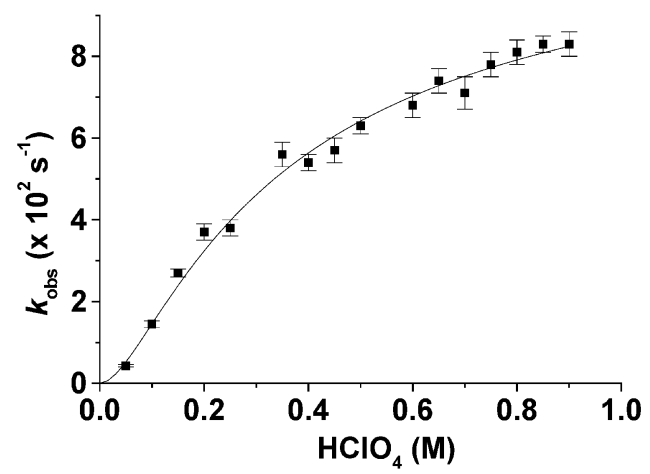

Fig. 5 Pseudo-first-order rate constants $k_{o b s}$ relative to the dissociation of $\mathrm{Eu}_{2} \mathrm{~L}_{3}$ in water at $25.0 \pm 0.2{ }^{\circ} \mathrm{C}$ as a function of $\left[\mathrm{HClO}_{4}\right]_{\text {tot }}$. Data are calculated from the gated luminescence experiments. Uncertainties are given as $3 \sigma$.

\section{Reaction mechanism}

Combining absorption and luminescence data, we were able to fit the dependence of the pseudo-first-order rate constants on the acid concentration to the following equation:

$$
k_{\mathrm{obs}}=\frac{a\left[\mathrm{H}^{+}\right]_{\mathrm{tot}}^{2}}{1+b\left[\mathrm{H}^{+}\right]_{\mathrm{tot}}+c\left[\mathrm{H}^{+}\right]_{\mathrm{tot}}^{2}}
$$

The relevant dissociation mechanism is described by eqns. (3)-(7) which include two fast protonation equilibria [eqns. (3) and (4)] followed by a rate-limiting step [eqn. (5)], the final decomplexation stages being faster [eqns. (6) and (7)]:

$$
\begin{gathered}
\mathrm{Eu}_{2} \mathrm{~L}_{3}+\mathrm{H} \stackrel{K_{1}}{\rightleftarrows} \mathrm{Eu}_{2} \mathrm{~L}_{3} \mathrm{H} \\
\mathrm{Eu}_{2} \mathrm{~L}_{3} \mathrm{H}+\mathrm{H} \stackrel{K_{2}}{\rightleftarrows} \mathrm{Eu}_{2} \mathrm{~L}_{3} \mathrm{H}_{2} \\
\mathrm{Eu}_{2} \mathrm{~L}_{3} \mathrm{H}_{2} \stackrel{k}{\longrightarrow} \mathrm{Eu}_{2} \mathrm{~L}_{2}+\mathrm{LH}_{2} \\
\mathrm{Eu}_{2} \mathrm{~L}_{2}+4 \mathrm{H} \stackrel{\text { fast }}{\longrightarrow} 2 \mathrm{Eu}+2 \mathrm{LH}_{2} \\
\mathrm{LH}_{2}+\mathrm{nH} \stackrel{\text { fast }}{\longrightarrow} \mathrm{LH}_{(2+\mathrm{n})}
\end{gathered}
$$

The parameters $a=k K_{1} K_{2}, b=K_{1}$ and $c=K_{1} K_{2}$ were determined by non-linear least-squares methods ${ }^{16}$ and are listed in Table 2. It is noteworthy that the values determined by gated luminescence spectrophotometry are in excellent agreement with those obtained using UV-visible absorption spectroscopy, within experimental errors.

We propose a process via the thermodynamic "prehelicate" $\mathrm{Eu}_{2} \mathrm{~L}_{2}$, which is the key intermediate ${ }^{11,12}$ of the self-assembly process mechanism of the di-europium triple-stranded helicate. The dinuclear mono-stranded $\mathrm{Eu}_{2} \mathrm{~L}$ intermediate is less likely, since it was only observed when europium(III) was in large excess with respect to the ligand. ${ }^{11}$ It strongly suggests that the

Table 2 Dissociation mechanism of the $\mathrm{Eu}_{2} \mathrm{~L}_{3}$ helicate in water at 25.0 $\pm 0.2{ }^{\circ} \mathrm{C}$ : thermodynamic and kinetic data

\begin{tabular}{lll}
\hline Step & Absorption $^{a}$ & Gated luminescence $^{b}$ \\
\hline $\mathrm{Eu}_{2} \mathrm{~L}_{3}+\mathrm{H} \stackrel{K_{1}}{\rightleftarrows} \mathrm{Eu}_{2} \mathrm{~L}_{3} \mathrm{H}$ & $K_{1}=9(3) \mathrm{M}^{-1}$ & $K_{1}=9(3) \mathrm{M}^{-1}$ \\
$\mathrm{Eu}_{2} \mathrm{~L}_{3} \mathrm{H}+\mathrm{H} \stackrel{K_{2}}{\rightleftarrows} \mathrm{Eu}_{2} \mathrm{~L}_{3} \mathrm{H}_{2}$ & $K_{2}=2.3(1.2) \mathrm{M}^{-2}$ & $K_{2}=3.2(1.1) \mathrm{M}^{-2}$ \\
$\mathrm{Eu}_{2} \mathrm{~L}_{3} \mathrm{H}_{2} \stackrel{k}{\longrightarrow} \mathrm{Eu}_{2} \mathrm{~L}_{2}+\mathrm{LH}_{2}$ & $k=0.12(1) \mathrm{s}^{-1}$ & $k=0.115(5) \mathrm{s}^{-1}$ \\
$\mathrm{Eu}_{2} \mathrm{~L}_{2}+4 \mathrm{H} \stackrel{\text { fast }}{\longrightarrow} 2 \mathrm{Eu}+2 \mathrm{LH}_{2}$ & $n . d$. & $n . d$. \\
${ }^{a} \mathrm{UV}$-visible absorption & spectroscopy; $\lambda=345 \mathrm{~nm} .{ }^{b}$ Europium- \\
centred emission: $\lambda_{\text {exc }}=324 \mathrm{~nm} ; \lambda_{\text {ana }}=595 \mathrm{~nm}$. Calculated errors \\
are given within parentheses. $n$. $d$. means not determined.
\end{tabular}

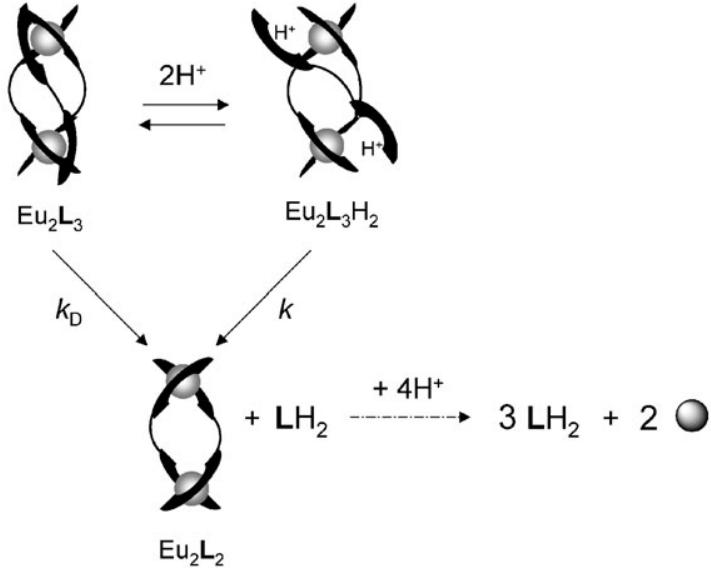

Fig. 6 Schematic representation of the dissociation mechanism.

two initial protonation reactions occur on the same ligand strand and lead to the rate-limiting disentanglement of the first diprotonated ligand. The schematic representation of the dissociation mechanism is given in Fig. 6 .

The two fast proton-dependent equilibria $(\log \bar{K}=0.95 \pm$ $0.15, \log \bar{K}_{2}=0.44 \pm 0.19$ ), could be assigned to the successive protonation of the two carboxylate groups of ligand L. The difference between these two constants is close to the value ( $\Delta \log K=0.6)$ which is expected for a statistic model ${ }^{17}$, and suggests weak interactions, especially electrostatic repulsions, between the respective coordination cavities of the two europium cations. The rate-limiting step observed under our experimental conditions is then associated with the disentanglement of the first diprotonated ligand strand, leading to $\mathrm{Eu}_{2} \mathrm{~L}_{2}$. Protonation and dissociation of the dinuclear double stranded helicate is then assumed to process rapidly. Our study points out the crucial role played by the reactive $\mathrm{Eu}_{2} \mathrm{~L}_{2}$ species as well as in the formation and in the dissociation mechanism of $\mathrm{Eu}_{2} \mathrm{~L}_{3}$. Indeed, only strongly pre-organised structures will prevent fast dissociation reactions. The proton-assisted pathways dominate the mechanism under our experimental conditions in agreement with the low solvolysis rate constant $k_{\mathrm{D}}$ which we previously determined for $\mathrm{Eu}_{2} \mathrm{~L}_{3}\left(k_{\mathrm{D}}=4(1) \times 10^{-4} \mathrm{~s}^{-1}\right){ }^{11}$

\section{Conclusion}

A fruitful combination of absorption and gated luminescence spectrophotometry allowed us to fully characterise the dissociation mechanism of a di-europium triple-stranded helicate in water and under acidic conditions. As for the self-assembly mechanism, ${ }^{11}$ the dissociation process involves a key dimetallic double-stranded complex $\mathrm{Eu}_{2} \mathrm{~L}_{2}$. The fast protonation of the two carboxylate groups borne by one of the three strands indeed triggers its slow rate-limiting release. The unwrapping of the first strand dominates the whole process. The further dissociation steps of the double-stranded dimetallic $\mathrm{Eu}_{2} \mathrm{~L}_{2}$ are more rapid. Only triple-stranded helical arrangement efficiently prevents a fast attack of the protons leading to the complete dissociation of the starting complex. The solvolytic dissociation of $\mathrm{Eu}_{2} \mathrm{~L}_{3}$ in water is rather slow $\left(k_{\mathrm{D}}=4 \times 10^{-4} \mathrm{~s}^{-1}\right)^{11}$ and is catalysed by $\mathrm{H}^{+}$ions $\left(k=0.12(3) \mathrm{M}^{-1} \mathrm{~s}^{-1}\right)$. As a conclusion, the europium helicate studied here is characterised by a high kinetic inertness over a wide range of $\mathrm{pH}(3<\mathrm{pH}<12)$ and by a large thermodynamic stability in water. ${ }^{7 \mathrm{~d}}$ These properties open the way for the preparation of novel luminescent biomarkers.

\section{Experimental section}

\section{Starting materials and solvents}

Ligand $\mathrm{L}$ was synthesised according to previously published procedure. ${ }^{7 \mathrm{c}, \mathrm{d}} \mathrm{Eu}\left(\mathrm{ClO}_{4}\right)_{3} \cdot \mathrm{nH}_{2} \mathrm{O}$ was prepared from the oxide 
(Rhône-poulenc, 99.99\%) in the usual way. ${ }^{18}$ CAUTION! Although we have experienced no problems in handling perchlorate compounds, these salts combined with organic ligands are potentially explosive and should be handled in small quantities and with the adequate precautions. ${ }^{19}$ Distilled water was further purified by passing it through a mixed bed of ion-exchanger (Bioblock Scientific R3-83002, M3-83006) and activated carbon (Bioblock Scientific ORC-83005). It was de-oxygenated by bubbling oxygen free argon (Sigma Oxiclear cartridge).

\section{UV-visible absorption}

The europium(III) complex $\left(7.22 \times 10^{-6} \mathrm{M}\right)$ was prepared at $\mathrm{p}[\mathrm{H}] \approx 6.0$ in water by adding 0.66 equivalent of europium(III) perchlorate to L. Perchloric acid $(70 \%$ in water, double distilled, Aldrich) was used as a scavenger and its concentration was ascertained by colorimetric titration with $\mathrm{NaOH}$ $\left(10^{-1} \mathrm{M}\right.$, Carlo Erba, Titrisol Normex) and phenolphthalein (Prolabo, purum). The dissociation reaction of the europiu$\mathrm{m}(\mathrm{III})$ helicate maintained at $25.0(2){ }^{\circ} \mathrm{C}$ (Lauda M12 thermostat) was monitored on a SX-18MV stopped-flow spectrophotometer from Applied Photophysic. Pseudo-first-order conditions with respect to the complex were used and acid concentrations were varied from $4.65 \times 10^{-2} \mathrm{M}$ to $8.34 \times 10^{-1}$ M. The absorbance decay versus time was monitored at 345 $\mathrm{nm}$ with a $1 \mathrm{~cm}$ optical cell. The data sets, averaged out of at least three replicates, were analysed with the commercial software Biokine. ${ }^{20}$ This program fits up to three exponential functions to the experimental curves with the Simplex algorithm $^{21}$ after initialisation with a Padé-Laplace method. ${ }^{22}$ Time-resolved absorption spectra were also collected from $280 \mathrm{~nm}$ to $450 \mathrm{~nm}$ using an Applied Photophysics diode array device. The multiwavelength data sets were treated by nonlinear least-squares analysis with the Specfit program. ${ }^{23}$ Specfit uses factor analysis to reduce the absorbance matrix and to extract the eigenvalues prior to the multiwavelength fit of the reduced data set according to the Marquardt algorithm. ${ }^{24,25}$

\section{Gated luminescence}

The concentration of the europium(III) complex was $6.08 \times$ $10^{-7} \mathrm{M}$ and the acid concentrations were varied from $5.00 \times 10^{-2} \mathrm{M}$ to $9.50 \times 10^{-1} \mathrm{M}$. Gated luminescence kinetic measurements were recorded at $25.0(2){ }^{\circ} \mathrm{C}$ (Haake FJ thermostat) on a Perkin-Elmer LS-50B. The excitation wavelength was set to 324(1) nm and the intensity decay of the ${ }^{5} \mathrm{D}_{0} \rightarrow{ }^{7} \mathrm{~F}_{1}$ transition at 595(1) nm was measured. Gated luminescence measurements were obtained using phosphorimeter acquisition, with a delay time of $0.05 \mathrm{~ms}$, a $200 \mathrm{~ms}$ sample window, 1 ms per flash and 1 flash per point. The slit widths were $12.5 \mathrm{~nm}$ for the excitation and emission. The data sets, averaged out of at least three replicates, were recorded and analysed with the commercial software Biokine. ${ }^{20}$

\section{Acknowledgements}

This work has been supported by the Centre National de la Recherche Scientifique (CNRS, UMR 7509) and the Swiss National Science Foundation. J. H. thanks the European Community for granting him a Marie Curie fellowship.

\section{References}

1 Lanthanide and Actinides, S. Cotton, McMillan education (Physical science series), London, 1991.

2 (a) G. Mathis, in Rare Earths, R. Saez-Puche and P. Caro, Eds., Editorial Complutense, Madrid, 1998; (b) Bioanalytical Applications of Labelling Technologies, I. Hemmilä, T. Ståhlberg and
P. Mottram, Wallac Oy, Turku, $2^{\text {nd }}$ ed., 1995; (c) I. Hemmilä and V. M. Mukkala, Crit. Rev. Clin. Lab. Sci., 2001, 38, 441-519; (d) Lanthanide Probes in Life, Chemical and Earth Sciences: Theory and Practice, J.-C. G. Bünzli and G. R. Choppin, Eds, Elsevier Science Publ. B.V., Amsterdam, 1989.

3 (a) J.-C. G. Bünzli in Metal Ions in Biological Systems, A. Sigel and H. Sigel, Eds., Marcel Dekker Inc., New York, 2004, 42, Ch. 2, pp. 39-75; (b) The Chemistry of Contrast Agents in Medical Magnetic Resonance Imaging, A. E. Merbach and E. Tóth, Eds, Wiley, London, 2001.

4 D. J. Bornhop, J. M. M. Griffin, T. S. Goebel, M. R. Sudduth, B. Bell and M. Motamedi, Appl. Spectrosc., 2003, 57, 1216-1222.

5 (a) P. B. Glover, P. R. Ashton, L. J. Childs, A. Rodger, M. Kercher, R. M. Williams, L. De Cola and Z. Pikramenou, J. Am. Chem. Soc., 2003, 125, 9918-9919; (b) D. Imbert, M. Cantuel, J.-C. G. Bünzli, G. Bernardinelli and C. Piguet, J. Am. Chem. Soc., 2003, 125, 15698-15699.

6 (a) J.-C. G. Bünzli, N. André, M. Elhabiri, G. Muller and C. Piguet, J. Alloys \& Compds, 2000, 303-304, 66-74; (b) C. Piguet and J.-C. G. Bünzli, Chem. Soc. Rev., 1999, 28, 347-358.

7 (a) C. Piguet, J.-C. G. Bünzli, G. Bernardinelli, G. Hopfgartner and A. F. Williams, J. Am. Chem. Soc., 1993, 115, 8197-8206; (b) N. Martin, J.-C. G. Bünzli, V. McKee, C. Piguet and G. Hopfgartner, Inorg. Chem., 1998, 37, 577-589; (c) M. Elhabiri, R. Scopelliti, J.-C. G. Bünzli and C. Piguet, Chem. Commun., 1998, 2347-2348; (d) M. Elhabiri, R. Scopelliti, J.-C. G. Bünzli and C. Piguet, J. Am. Chem. Soc., 1999, 121, 10747-10762; (e) C. Platas, M. Elhabiri, M. Hollenstein, J.-C. G. Bünzli and C. Piguet, J. Chem. Soc., Dalton Trans., 2000, 2031-2043; (f) R. Triper, M. Hollenstein, M. Elhabiri, A. S. Chauvin, G. Zucchi, C. Piguet and J.-C. G. Bünzli, Helv. Chim. Acta, 2002, 85, 1915-1929.

8 (a) N. André, R. Scopelliti, G. Hopfgartner, C. Piguet and J.-C. G. Bünzli, Chem. Commun., 2002, 214-215; (b) N. André, T. B. Jensen, R. Scopelliti, D. Imbert, M. Elhabiri, G. Hopfgartner, C. Piguet and J.-C. G. Bünzli, Inorg. Chem., 2004, 43, 515-529.

9 J.-C. G. Bünzli and C. Piguet, Chem. Rev., 2002, 102, 1897-1928.

10 S. Floquet, M. Borkovec, G. Bernardinelli, A. Pinto, L. A. Leuthold, G. Hopgartner, D. Imbert, J.-C. G. Bünzli and C. Piguet, Chem. Eur. J., 2004, 10, 1091-1105.

11 M. Elhabiri, J. Hamacek, J.-C. G. Bünzli and A. M. AlbrechtGary, Eur. J. Inorg. Chem., 2004, 51-62.

12 J. Hamacek, S. Blanc, M. Elhabiri, E. Leize, A. Van Dorsselaer, C. Piguet and A. M. Albrecht-Gary, J. Am. Chem. Soc., 2003, 125, 1541-1550.

13 N. Fatin-Rouge, S. Blanc, A. Pfeil, A. Rigault, A. M. AlbrechtGary and J. M. Lehn, Helv. Chim. Acta, 2001, 84, 1694-1711.

14 N. Fatin-Rouge, S. Blanc, E. Leize, A. Van Dorsselaer, P. Baret, J. L. Pierre and A. M. Albrecht-Gary, Inorg. Chem., 2000, 39, 57715778.

15 (a) E. Kiss, K. Petrohán, D. Sanna, E. Garribba, G. Micera and T. Kiss, Polyhedron, 2000, 19, 55-61; (b) R. I. Gelb and J. S. Alper, J. Chem. Eng. Data 1998, 43, 383-385; (c) R. W. Green and H. K. Tong, J. Am. Chem. Soc., 1956, 78, 4896-4900; (d) R. M. Dyson, G. A. Lawrence, H. Mäcke and M. Maeder, Polyhedron, 1999, 18, 3243-3251.

16 Microcal $^{\mathrm{TM}}$ Origin $^{\mathrm{TM}}$, Microcal Software, Inc., Northampton, USA.

17 B. Perlemutter-Hayman, Acc. Chem. Res., 1986, 19, 90-96.

18 J. F. Desreux, Lanthanide Probes in Life, Chemical and Earth Sciences. Theory and Practice, Eds., J.-C. G. Bünzli and G. R. Choppin, Elsevier Science Publ. B. V., Amsterdam, 1989.

19 K. N. Raymond, Chem. Eng. News, 1983, 61, 4.

20 Bio-Logic Company, Ed. Bio-Logic Company, Echirolles, 1991.

21 J. A. Nelder and R. Mead, The Computer Journal, 1965, 7, 308-313.

22 E. Yeramian and P. Claverie, Nature, 1987, 326, 169-174.

23 (a) R. A. Binsteadt and A. D. Zuberbülher, Specfit, A Program for Global Least Squares Fitting of Equilibrium and Kinetics Systems Using Factor Analysis \& Marquardt Minimisation, Version 2-11 C, 1998, Spectrum Software Associates, Chapel Hill; (b) H. Gampp, M. Maeder, C. J. Meyer and A. D. Zuberbühler, Talanta, 1985, 32, 95-101; (c) F. J. C. Rossotti, H. S. Rossotti and R. J. Whewell, J. Inorg. Nucl. Chem., 1971, 33, 2051-2065; (d) H. Gampp, M. Maeder, C. J. Meyer and A. D. Zuberbühler, Talanta, 1985, 32, 257-264; (e) H. Gampp, M. Maeder, C. J. Meyer and A. D. Zuberbühler, Talanta, 1986, 33, 943-951.

24 D. W. Marquardt, J. Soc. Indust. Appl. Math., 1963, 11, 431-441.

25 M. Maeder and A. D. Zuberbühler, Anal. Chem., 1990, 62, 22202224 . 